\title{
Financial Variables and Euro Area Growth: A Non-parametric Causality Analysis
}

\author{
Ekaterini Panopoulou* \\ University of Piraeus, Greece \& IIIS, Trinity College Dublin
}

April 5, 2007

\begin{abstract}
This paper investigates the predictive ability of financial variables for euro area growth through bivariate and multivariate non-parametric Granger causality tests. Apart from assessing the within-country forecasting ability of commonly-employed financial variables, such as the term spread, the stock market returns and the growth of real money supply, we also test for cross-country influences. In this way, we reveal the countries that are more useful in predicting growth in other member countries along with the ones that are more receptive to other countries' financial developments. Our results suggest that financial variables are useful leading indicators for euro area growth at a joint level, albeit at different horizons, ranging from one to six quarters. Our finding of overall increased levels of receptivity among member states provides useful information for policy makers, especially in the case of monetary union such as the euro area.
\end{abstract}

JEL Classification: E52; C14;

Keywords: cross-correlations; Granger causality; money supply; output growth; term spread; stock returns;

Word count: 4.000 words

Acknowledgements: I am grateful to S. Kalyvitis, N. Pittis, D. Thomakos and F. Moneta for helpful suggestions and comments. The usual disclaimer applies.

\footnotetext{
* Correspondence to: Ekaterini Panopoulou Department of Statistics and Insurance Science, University of Piraeus, Greece. Email: apano@unipi.gr. Tel: 00302104142728 . Fax: 00302104142340.
} 


\section{Introduction}

A vast literature in finance and macroeconomics is devoted to the forecasting ability of financial variables for real economic activity. Empirical evidence is mixed and results are not robust with respect to model specification, sample choice and forecast horizon. ${ }^{1}$

The financial variables often employed in empirical studies are the ones identified as leading indicators of economic activity, such as stock returns, interest rates, interest rate spreads, and monetary aggregates. Among the many studies that establish the forecasting ability of stock market returns for output growth are Goldsmith (1969), Bosworth (1975), Hall (1978), Fama (1981), Geske and Roll (1983), as well as more recent studies by Barro (1990), Fama (1990), Schwert (1990), Estrella and Mishkin (1998), Hassapis and Kalyvitis (2002), Hassapis (2003) and Panopoulou et al. (2006). These studies find that stock returns are highly correlated with future real activity, for various data frequencies covering very long periods, and are robust to alternative definitions of the data series. Over the last years many researchers have revealed a positive association between the yield spread and future economic activity. With respect to monetary aggregates, these are often linked to the monetary stance and as a result to expectations for future growth and inflation. Among the plethora of studies that find that the term structure and/or monetary aggregates are associated with future economic activity, are the ones by Stock and Watson (1989), Harvey (1988, 1997), Estrella and Hardouvelis (1991), Plosser and Rouwenhorst (1994), as well as the more recent ones by Estrella and Mishkin (1997, 1998), Hassapis et al. (1999), Black et al. (2000), Galbraith and Tkacz (2000), and Hamilton and Kim (2002). There is evidence, however, that the forecasting ability of the term spread has fallen over the past decades (see, inter alia, Giacomini and Rossi, 2006).

With the exception of a few, the aforementioned studies have concentrated and examined the predictive ability of financial variables for US future growth. Similar ev-

\footnotetext{
${ }^{1}$ See Stock and Watson (2003) for a review of the empirical literature.
} 
idence for the euro area countries is quite scarce and more recent. Among the first to tackle this issue are Davis and Fagan (1997) who find that the yield curve improves the forecast ability of output growth for the six out of the nine European countries examined. Sensier et al. (2004) examine the roles of domestic and international variables in predicting business cycle regimes in four European countries, namely Germany, France, Italy and the UK and find that real money growth and stock market prices are important for all countries except for Germany and Italy, albeit with differing signs and lag lengths. The yield curve, however, cannot beat the separate use of either long-term or short term rates, which are found to be significant with mostly a negative effect. On the contrary, Moneta (2005) finds that the yield spread is the single most powerful predictor of recessions in the euro area especially for forecasting horizons beyond one quarter. The same conclusion is reached by Duarte et al. (2005), who use aggregate data for the euro area over the period 1970-2004 and confirm the ability of the yield curve as a leading indicator for output growth and future recessions. Employing an extensive list of leading indicators, Banerjee et al. (2005) find that measures of shortand long-term interest rates as well as the interest rate spread are among the best performing single indicators for GDP growth. More recently, Panopoulou (2007) finds that financial variables manage to improve forecast precision for some country and at some horizon with the most prominent variable being the stock market returns that improves forecasts in the majority of the cases considered.

Contrary to the traditional approach that concentrates on single equation and multivariate parametric models in order to assess the forecasting performance of a set of financial variables, we take another route and reinvestigate systematically the relationship between financial variables and growth by using non-parametric Granger causality tests. Employing monthly data for the euro area countries, we first investigate the bivariate relationship between a set of financial variables and output growth in the context of the methodology proposed by Cheung and $\mathrm{Ng}(1996) .^{2}$ This non-parametric Granger

\footnotetext{
${ }^{2}$ The methodology put forward by Cheung and Ng (1996) extends the one proposed by Haugh (1976)
} 
causality methodology is based on the residual cross-correlation function of the series under scrutiny and is robust to distributional assumptions, which are likely to be important since the variables at hand may exhibit both autocorrelation and conditional volatility effects. As a second step, following Lemmens et al. (2005) we extend our bivariate testing procedure to a multivariate one by pooling together the information from the whole panel of the euro area countries. This multivariate testing procedure, introduced by El Himdi and Roy (1997), enables us to investigate the general predictive content of a candidate financial variable for economic growth for the entire panel. Furthermore, it can be modified so as to reveal more information with respect to the interdependencies within the euro area. Specifically, it enables us to test whether developments in financial variables of one country affect real economic activity in the remaining countries, i.e. to discover a country's "clout". Similarly, we can test for the receptivity of a country, i.e. discover the countries that are more likely to be led by developments in the financial variables of the remaining ones in the euro area.

To the best of our knowledge, this multivariate testing methodology has been hardly employed in the literature. Specifically, El Himdi and Roy (1997), who proposed this methodology, applied this multivariate test to investigate the causal relations between money (M1 and M2) and income (Gross National Product) for Canada, as well as to study the causal directions between the Canadian and American economies. Lemmens et al. (2005) adapted the El Himdi and Roy (1997) test to jointly test the forecasting ability of multiple production expectation series for the members of the European Union. In this sense, they assessed whether part of the joint effect they found was due to crosscountry influences and they determined the countries which have the most 'clout', i.e. are more useful in predicting other countries' growth along with those that are influenced more by the others, i.e. they display more 'receptivity'.

The layout of this paper is as follows: Section 2 outlines the bivariate and multiof Cheung and $\mathrm{Ng}$ (1996), which filters out second-order effects prior to testing for causality in mean. 
variate Granger-causality testing procedures used for the empirical estimation of the relationship between growth and financial variables. Section 3 presents and comments on the empirical results for the euro area countries and section 4 summarizes the main findings of the paper.

\section{Econometric Methodology}

In this section, we briefly describe the non-parametric techniques utilised in the present study which aim at detecting any Granger causality running from financial variables to output growth. In subsections 2.1 and 2.2 we describe the bivariate and multivariate methodologies employed, respectively.

\subsection{Bivariate causality tests}

Consider a bivariate stationary and ergodic stochastic process $Z_{t}=\left[y_{t}, x_{t}\right]^{\top}, t=1,2, \ldots$ In our case, $y_{t}$, represents output growth and $x_{t}$, a financial variable. Cheung and $\mathrm{Ng}$ (1996) proposed a test based on the sample cross-correlations function of the standardised residuals and involves two stages. In the first stage, univariate time-series models are estimated for both the series under scrutiny, such as the typical $\operatorname{ARMA}(p, q)$ $\operatorname{GARCH}(1,1)$. In our case the correct order of the $\operatorname{ARMA}(p, q)$ model for the mean of the series is determined by means of the Schwartz Information Criterion (SIC). In the second stage, we calculate the sample cross-correlations of the standardised residuals, typically defined as follows:

$$
\begin{aligned}
& \widehat{u}_{y t}=\left(y_{t}-\widehat{\mu}_{y, t}\right) / \widehat{h}_{y, t} \\
& \widehat{u}_{x t}=\left(x_{t}-\widehat{\mu}_{x, t}\right) / \widehat{h}_{x, t}
\end{aligned}
$$

where $\widehat{\mu}_{y, t}, \widehat{\mu}_{x, t}$ and $\widehat{h}_{y, t}, \widehat{h}_{x, t}$ are the estimated conditional means and variances of output growth and a candidate financial variable, respectively. 
The sample cross-correlation function of $u_{y t}$ and $u_{x t}\left(\widehat{\tau}_{x, y}(k)\right)$ is given by:

$$
\widehat{\tau}_{x, y}(k) \equiv \frac{\widehat{C}_{x, y}(k)}{\sqrt{\widehat{C}_{x, x}(0) \widehat{C}_{y, y}(0)}}
$$

where $\widehat{C}_{x, y}(k)=\begin{array}{ll}T^{-1} \sum_{t=k+1}^{T}\left[\widehat{u}_{y t} \widehat{u}_{x t-k}\right], & k \geqq 0 \\ T^{-1} \sum_{t=-k+1}^{T}\left[\widehat{u}_{y t+k} \widehat{u}_{x t}\right], & k<0\end{array}$ is the sample cross-covariance, $\widehat{C}_{x, x}(0)$, $\widehat{C}_{y, y}(0)$ are the sample variances of one of the financial variables and output growth, respectively, $k$ is the lag length employed and $T$ is the sample size. The test statistic, $S$, proposed by Cheung and $\mathrm{Ng}$ (1996) is given by the following formula:

$$
S_{x \rightarrow y}=T \sum_{k=1}^{M} \widehat{\tau}_{x, y}^{2}(k)
$$

where $M$ is a bandwidth parameter which under the null hypothesis of no causality in mean from $x_{t}$ to $y_{t}$ follows asymptotically a chi-square distribution with $M$ degrees of freedom $\left(X_{M}^{2}\right)$. Similarly, when testing for causality in mean running from $y_{t}$ to $x_{t}$, $S_{y \rightarrow x}=T \sum_{k=-M}^{-1} \widehat{\tau}_{x, y}^{2}(k)$ is utilised. Finally, $S_{x \leftrightarrow y}=T \sum_{k=-M}^{M} \widehat{\tau}_{x, y}^{2}(k)$ can be used to test for bidirectional causality-in-mean. We should also note that in order to obtain correct inference, $M$ should be large enough to include all potential nonzero crosscorrelations.

\subsection{Multivariate causality tests}

Let $Y_{t}$ and $X_{t}$ be two multivariate time series with $Y_{t} \in R^{d 1}$ and $X_{t} \in R^{d 2}$. In our case, the dimension of these multivariate time-series is $d=d_{1}=d_{2}=12$, the number of the euro area countries under scrutiny. El Himdi and Roy (1997), extended the bivariate methodology of Haugh (1976) to the multivariate case. They proposed a test statistic for the hypothesis of no Granger causality between multivariate series. Similar to the bivariate case, the multivariate time series are prefiltered separately through 
Vector Autoregressive GARCH (VAR-GARCH) models. ${ }^{3}$ In this respect, the residual series $U_{y t}$ and $U_{x t}$, obtained after filtering with a VAR model, are independent of the past of every single component of $Y_{t}$ and $X_{t}$, respectively. ${ }^{4}$ The estimated standardised residuals,

$$
U_{y t}=\left(\begin{array}{c}
u_{y 1, t} \\
u_{y 2, t} \\
\vdots \\
u_{y d_{1}, t}
\end{array}\right) \text { and } U_{x t}=\left(\begin{array}{c}
u_{x 1, t} \\
u_{x 2, t} \\
\vdots \\
u_{x d_{2}, t}
\end{array}\right)
$$

are cross-correlated with cross-correlation function

$$
\widehat{R}_{x, y}(k)=\left(\begin{array}{llll}
\widehat{\tau}_{x_{1}, y_{1}}(k) & \widehat{\tau}_{x_{1}, y_{2}}(k) & \ldots & \widehat{\tau}_{x_{1}, y_{d_{1}}}(k) \\
\vdots & & & \vdots \\
\widehat{\tau}_{x_{d_{2}, y_{1}}}(k) & \ldots & \ldots & \widehat{\tau}_{x_{d_{2}, y_{d_{1}}}}(k)
\end{array}\right) \in R^{d_{2} \times d_{1}}
$$

with $\widehat{\tau}_{x_{i}, y_{i}}(k)$ defined in (1). Similarly, we define the corresponding autocorrelations of $X_{t}$ and $Y_{t}, \widehat{R}_{x, x}(k) \in R^{d_{2} \times d_{2}}$ and $\widehat{R}_{y, y}(k) \in R^{d_{1} \times d_{1}}$. The test statistic proposed by El Himdi and Roy (1997) is given by the following formula:

$$
S_{M}=T \sum_{k=-M}^{M}\left[\operatorname{vec}\left(\widehat{R}_{x, y}(k)\right)\right]^{T} A^{-1}\left[\operatorname{vec}\left(\widehat{R}_{x, y}(k)\right)\right]
$$

where $A$ is the asymptotic covariance matrix of $\sqrt{T} \operatorname{vec}\left(\widehat{R}_{x, y}(k)\right)$, that is $A=\widehat{R}_{x, x}(k) \otimes$ $\widehat{R}_{y, y}(k)$. When testing for causality in the mean running from $x_{t}$ to $y_{t}$, only positive values of the bandwidth parameter $M$ should be employed. In this case, the above quadratic form is shown to follow a $X_{M d_{1} d_{2}}^{2}$ distribution. In the case that we are interested in revealing bidirectional causality between the series at hand, i.e. allowing for both positive and negative lags, the degrees of freedom are adjusted accordingly to

\footnotetext{
${ }^{3}$ The order of each VAR is determined by the SIC criterion.

${ }^{4}$ Please note that these series differ from the ones employed in the bivariate tests. Specifically, the ones obtained with respect to the within country VARs may still carry information for the other countries.
} 
$(2 M+1) d_{1} d_{2}$.

Naturally, this multivariate test is more powerful as opposed to the bivariate one introduced in Section 2.1 due to mainly two reasons. First, all countries are pooled together in order to find evidence of Granger causality and second, Granger causality across countries is also allowed. Moreover, this testing procedure can be modified so as to reveal more information with respect to the interdependencies within the euro area. Specifically, if we are interested in testing whether the developments in financial variables of one country affect real economic activity in the remaining countries, i.e. to discover a country's "clout", we only include the financial variable $x_{i}$ of country $i$ and test whether it causes the variables $y_{j}$, with $j \neq i$. In such a case, $d_{1}=1$ and $d_{2}=d-1$, with $d$ the number of countries participating in the panel. Similarly, we can test for the receptivity of a country, i.e. discover the countries that are more likely to be led by developments in the financial variables of the remaining ones in the euro area. In this case, we test whether real economic activity in country $j$ is Granger-caused by the financial variables $x_{i}$ of the remaining countries, with $i \neq j$. The test again follows a $X^{2}$ distribution with $M(d-1)$ degrees of freedom.

\section{Empirical Evidence}

In this section we apply the techniques outlined in the previous section to examine the empirical relationship between growth and financial variables in the euro area. ${ }^{5}$ The financial variables considered are the term spread, real stock market returns and real money supply growth for the 12 euro area countries. Our data set is monthly and covers the period from January 1988 to May 2005. ${ }^{6}$ As a measure of the growth rate of output we use the industrial production index (seasonally adjusted) from the OECD Economic Indicators (obtained by Datastream). Following Fama (1990) and

\footnotetext{
${ }^{5}$ All the reported results were obtained by programs written in E-views 4.1 and are available from the author upon request.

${ }^{6}$ To ensure homogeneity of our results, especially for our multivariate procedures, we employed the longest dataset possible for which data were available for the 12 euro area countries.
} 
other authors, stock market returns were obtained by use of Datastream-calculated composite indices and were appropriately adjusted for the inflation rate of the countries under consideration. The term spread is calculated as the difference between a longterm bond yield, mainly a 10-year one, and a short-term interest rate, mainly a threemonth Treasury Bill obtained from the IMF, International Financial Statistics (Source: EcoWin). ${ }^{7}$ As regards the monetary aggregates, we employed the M3 money supply, CPI deflated (Source: Datastream).

\subsection{Bivariate predictive content}

We begin the empirical analysis with the within-country forecasting ability of the term spread, assessed via the bivariate Granger causality tests analyzed in Section 2.1 with the bandwidth set at 15 months (5 quarters). ${ }^{8}$ The relevant $p$-values for testing the hypothesis of interest, i.e. no causality from the term spread to future growth are reported on the main diagonal of Table 1. Our findings confirm the mixed evidence found in the literature concerning the within-country predictive ability of the term spread. Specifically, Granger causality is detected in 5 of the 12 euro area countries, namely Austria, Belgium, France, Germany and the Netherlands. Evidence is particularly strong in the cases of Belgium, Germany and the Netherlands as the corresponding $p$-values are lower than 1\%. Our results reinforce the findings of Davis and Fagan (1997), who using parametric methods and a similar dataset found that the term spread improves forecasts of output growth in Belgium, Germany, France and the Netherlands.

\section{[INSERT TABLE 1 HERE]}

Next, we extend the bivariate causality tests to allow for dependence between the term spread in one country and real activity in the remaining countries. The respective $p$-values are reported in the off-diagonal elements of Table 1. More in detail, the

\footnotetext{
${ }^{7}$ Moneta (2005) finds that the most informative term spread for future growth in the euro area is the one between the 10-year bond and the 3-month interbank rate when comparing over ten alternative specifications.

${ }^{8}$ The bandwidth is set approximately equal to $\sqrt{T}, T$ is our sample size.
} 
$(i, j)$ element corresponds to the $p$-value for the test that the term spread in country $j$ Granger causes output growth in country $i$. Approximately one third of the 132 off-diagonal elements appear significant, suggesting the existence of substantial crosscountry influences. Interestingly, developments in the term spread of Austria, Germany and France appear to have predictive ability over more than half of the euro area members' growth. The finding with respect to Germany and France is quite expected as these countries represent the driver forces behind the unification of Europe and are the more important euro area countries in terms of GDP. Especially for Germany, the German dominance hypothesis is quite established in the literature. Among others, Artis and Zhang (1998) and Barassi et al. (2005) find evidence of the leading role of German interest rates. Similarly, Moneta (2005) finds that among Germany, France and Italy, the German term spread seems to have the strongest predictive power for euro area growth as a whole. The clout of Austria, however, seems to be puzzling. One possible explanation is that it actually reflects its proximity and its close economic, political and cultural link to Germany. Given that the bivariate testing methodology does not filter cross-country correlations beforehand, it seems possible that increased correlations between financial variables and growth of the countries may emerge as strong causality patterns. Our multivariate procedures (see section 3.2) take this effect into account.

Our results with respect to market returns are reported in Table 2. Starting with the diagonal elements, we find significant links existing between stock market returns and real growth for half of the euro area countries. Specifically, we cannot reject the null of no Granger causality for Belgium, Finland, France, Germany, Italy and Spain. Given that the majority of these countries are the more developed in the euro area, our findings suggest that stock market returns act as a leading indicator in such countries. As pointed out by Mauro (2003), the association between stock market returns and growth is stronger in countries with high market capitalization such as the UK and the US. 


\section{[INSERT TABLE 2 HERE]}

Turning to the cross-country influences, significant evidence of cross-country influences between returns and growth is found similarly to the case of the term spread. Among the countries with the highest predictive ability over others are Finland, France, Germany, Portugal and Spain.

Finally, we examine the predictive ability of real money growth for output. The respective figures are tabulated in Table 3.

\section{[INSERT TABLE 3 HERE]}

Interestingly, the evidence seems to be weaker compared to the other two variables. Our within-country tests suggest that only in Austria, Finland, Ireland and Spain, Granger causality from money to growth cannot be rejected. Our findings are in line with Stock and Watson (2003) that find the real M3 growth does not improve forecasts for growth 4 quarters ahead for France and Germany. Furthermore, cross-country linkages as far as monetary aggregate developments are concerned seem to be weak. Austria, Belgium and France are the countries that seem to affect more than four other member countries.

As aforementioned, the bivariate causality results should be interpreted with cautiousness due to the multiple testing problem, as well, which might lead to our estimates being biased downwards (see Bauer et al., 1988 and Lemmens et al., 2005). The problems associated with the bivariate testing environment can easily be addressed when extending our testing procedures to a multivariate framework. These results are discussed in the next subsection.

\subsection{Multivariate predictive content}

Turning to the joint testing of Granger causality, our results paint a different picture. Table 4 reports the test statistics and the corresponding $p$-values from the El Himdi 
and Roy (1997) test for causality between growth and financial variables at a joint euro area level and for a variety of bandwidths ranging from 3 to 18 months (one to six quarters). Allowing for various bandwidths when detecting causality enables us to gain some insight on the lag with which changes in financial variables affect economic activity. As a result informal guidance for the lag structure of parametric models is provided.

\section{[INSERT TABLE 4 HERE]}

Starting with the term spread, our results suggest that it can be a useful indicator for future euro area growth particularly at horizons beyond one year. The respective $p$-values marginally indicate significance at a 6 months' horizon, while significance at the $5 \%$ level is obtained for the five- and six-quarter horizon. This finding is not at all surprising, since the predictive power of the term spread is typically found to be maximised at longer horizons, usually over one year. For example, Duarte et al. (2005), employing quarterly aggregate euro area data, find that the highest explanatory power of the term spread when a linear model is employed, is found between three and six quarters ahead, similar to findings for the US (see Estrella and Mishkin, 1998).

Stock market developments for the euro area as a whole seem to provide limited information on future growth, since evidence of Granger causality from returns to growth is limited and confined to a two-quarter horizon. This is quite expected, though, given that the majority of the euro area countries did not have a developed stock market until recently. The horizon at which we detect the strongest association between stock market and output growth is consistent with US findings (Fama, 1990 and Schwert, 1990 among others) and some limited evidence for the euro area (see Sensier et al. 2004). Specifically, these studies find that the link between growth and stock returns is maximised at a forecast interval of two to four quarters.

Finally, monetary aggregates consistently lead euro area economic activity for horizons from one to five quarters. This result is in contrast with our bivariate analysis 
that indicated weak links between growth in money supply and output growth. The increased power of the multivariate tests due to the pooling of observations from the 12 countries as well as the prefiltering of the series may have led to clearer detection of the causality pattern. This finding complements the analysis of Sensier et al. (2004) who find that real money growth is important in predicting business cycle regimes in Europe.

Table 5 provides a more in-depth analysis with respect to cross-country dependence. Specifically, the Table reports the relevant $p$-values for assessing both the leading role ('clout') of each of the euro area countries' financial variables as well as their 'receptivity' to developments in the rest of the member countries.

\section{[INSERT TABLE 5 HERE]}

Developments in the term spread of Austria, Belgium, France, Germany and the Netherlands appear to be significant for the euro area countries, which on the whole appear quite receptive. The countries that appear to be non-responsive to developments in other countries' term spread are Ireland, Luxembourg and Portugal. Turning to stock returns, Austria, Germany and Italy appear to have significant 'clout'. On the other hand, nine out of the twelve euro area countries are receptive. Interestingly, Luxembourg and Portugal are included in the non-receptive countries along with Spain. As far as monetary aggregates are concerned, this subset of results conveys a similar message to the one of the multivariate test, i.e. increased interdependence. More in detail, the major countries, with the exception of Spain show the most clout and in terms of receptivity, only Ireland and Portugal appear secluded.

Overall, during the period under examination and excluding Ireland, Luxembourg and Portugal, the receptivity of all countries with respect to financial variables appears quite high justifying a monetary union. 


\section{Conclusions}

The bulk of empirical studies have employed parametric models in order to study the role of financial variables in forecasting growth. Given that inference within parametric models is affected when some of the underlying assumptions are violated for the dataset at hand, non parametric methods can prove valuable in this respect. Furthermore, with the exception of a few, parametric studies have concentrated mainly on the US. The creation of the euro area monetary union brings to the fore the assessment of the forecasting ability of financial variables for the euro area member countries. No systematic examination, either parametric or non-parametric of these relationships has been conducted so far for the 12 member states.

In an attempt to fill this void, this paper takes a new approach to testing whether financial variables are useful in forecasting euro area output growth by utilising both bivariate and multivariate non-parametric Granger causality tests. Our bivariate analysis revealed the within-country information content of financial variables along with the cross-country linkages. However, there is no a priori reason to disregard the information content in one country for the remaining members as well as for the whole panel. In this vein, our multivariate tests aimed at revealing the predictive content of financial variables at a joint euro area level and to uncover the member states that are more useful in predicting growth in other member countries along with the ones that are more receptive to other countries' financial developments.

In general, our results are consistent with existing studies for the euro area and to some extent the US and may be summarized as follows:

(i) Within-country bivariate causality tests suggest that both the term spread and stock market returns contain useful information for approximately half the euro area countries, while evidence with respect to real money growth is weaker.

(ii) Cross-country linkages in a bivariate framework point to similar findings. Specifically, significant causality patterns are detected for one third of the pairs examined for 
both the term spread and the stock market returns, while developments in monetary aggregates seem to carry reduced information across member states.

(iii) Our multivariate tests suggest that the information content of the term spread at a joint euro area level is maximised at a five to six quarter horizon, while the respective horizon for stock market returns is confined to two quarters. Contrary to our bivariate findings, monetary developments carry information for a variety of horizons ranging from one to five quarters.

(iv) In terms of 'clout', the German dominance hypothesis is confirmed as financial developments in Germany along with Austria appear to have significant impact on the remaining members. Furthermore, developments in a subset of Belgium, France, Italy and the Netherlands financial variables are significant for euro area countries' growth.

(v) As far as 'receptivity' is concerned, the majority of the countries appear open, with Ireland, Luxembourg and Portugal being the least responsive.

The methodology employed here can be employed to investigate any economic interdependencies for a panel of countries and complement parametric studies that leave empirical questions open. Another promising route for further research is modifying this multivariate testing framework to allow for a weighting scheme. In this way, countries may enter the panel with different weights, for example GDP weights and results will be more representative and informative for policymakers especially in the case of a monetary union. 


\section{References}

[1]Artis, M. J. and Zhang, W. (1998). 'The linkage of interest rates within the EMS', Weltwirtschaftliches Archiv, Vol. 134, pp. 117- 132.

[2]Banerjee, A., Masten, I. and Marcellino, M. (2005). 'Leading indicators for euro-area inflation and GDP growth', Oxford Bulletin of Economics and Statistics, Vol. 67, pp. $785-813$.

[3]Barassi, M. R., Caporale, G. M. and Hall, S. G. (2005). 'Interest rate linkages: A Kalman Filter Approach to detecting structural change', Economic Modelling, Vol. $22(2)$, pp. 253-284.

[4]Barro, R. (1990). 'The stock market and investment', Review of Financial Studies, Vol. 3, pp. 115-31.

[5]Bauer, P., Hommel, G. and Sonnemann, E. (1988). Multiple hypotheses testing. Berlin: Springer.

[6]Black, D., Corrigan, P. and Dowd, M. (2000). 'New dogs and old tricks: do money and interest rates still provide information content for forecast of output and prices?' International Journal of Forecasting, Vol. 16, pp. 191-205.

[7]Bosworth, B. (1975). 'The stock market and the economy' Brookings Papers on Economic Activity, Vol. 2, pp. 257-90.

[8]Cheung, Y.M. and Ng, L.K. (1996). 'A causality-in-variance test and its application to financial market prices', Journal of Econometrics, Vol. 72, pp. 33-48.

[9]Davis, E.P. and Fagan, G. (1997). 'Are financial spreads useful indicators of future inflation and output growth in EU countries', Journal of Applied Econometrics, Vol. 12, pp. 701-714. 
[10]Duarte, A., Venetis, I.A. and Paya, I. (2005) 'Predicting real growth and the probability of recession in the Euro area using the yield spread', International Journal of Forecasting, Vol. 21, pp. 261-277.

[11]El Himdi, K. and Roy, R. (1997). 'Tests for non-correlation of two multivariate ARMA time series' Canadian Journal of Statistics, Vol. 25, pp. 233-256.

[12]Estrella, A. and Hardouvelis, G. (1991). 'The term structure as a predictor of real economic activity', Journal of Finance, Vol. 46, pp. 555-76.

[13]Estrella, A. and Mishkin, F. (1997). 'The predictive power of the term structure of interest rates in Europe and the United States: implications for the European Central Bank', European Economic Review, Vol. 41, pp. 1375-1401.

[14]Estrella, A., and Mishkin, F. (1998). 'Predicting U.S. recessions: financial variables as leading indicators', Review of Economics and Statistics, Vol. 80, pp. 45-61.

[15]Fama, E. (1981). 'Stock returns, real activity, inflation and money', American Economic Review, Vol. 71, pp. 545-65.

[16]Fama, E. (1990). 'Stock returns, expected returns and real activity', Journal of Finance, Vol. 45, pp. 1089-1108.

[17]Galbraith, J. and Tkacz, G. (2000). 'Testing for asymmetry in the link between the yield spread and output in the G-7 countries', Journal of International Money and Finance, Vol. 19, pp. 657-72.

[18]Geske, R. and Roll, R. (1983). 'The monetary and fiscal linkage between stock returns and inflation', Journal of Finance, Vol. 38, pp. 1-33.

[19]Giacomini, R. and Rossi, B. (2006). 'How stable is the forecasting performance of the yield curve for output growth?', Oxford Bulletin of Economics and Statistics, Vol. 68, pp. 783-795. 
[20]Goldsmith, R. (1969). Financial Structure and Development, New Haven: Yale University Press.

[21]Hall, R. (1978). 'Stochastic implications of the life cycle-permanent income hypothesis: theory and evidence', Journal of Political Economy, Vol. 86, pp. 971-87.

[22]Hamilton, J. and Kim, D. (2002). 'A re-examination of the predictability of economic activity using the yield spread', Journal of Money, Credit and Banking, Vol. 34, pp. $340-360$.

[23]Harvey, C. (1988). 'The real term structure and consumption growth', Journal of Financial Economics, Vol. 22, pp. 305-33

[24]Harvey, C. (1997). 'The relation between the term structure of interest rates and Canadian economic growth'. Canadian Journal of Economics, Vol. 30, pp. 169-93.

[25]Hassapis, C. (2003). 'Financial variables and real activity in Canada', Canadian Journal of Economics, Vol. 36, pp. 421-442.

[26]Hassapis, C. and Kalyvitis, S. (2002). 'Investigating the links between growth and stock price changes with empirical evidence from the G7 economies', Quarterly Review of Economics and Finance, Vol. 42, pp. 543-75.

[27]Hassapis, C., Pittis, N. and Prodromides, K. (1999). 'Unit roots and Granger causality in the EMS interest rates: the German dominance hypothesis revisited', Journal of International Money and Finance, Vol. 18, pp. 47-73.

[28]Haugh, L.D. (1976). 'Checking the independence of two covariance-stationary time series: A univariate residual cross-correlation approach', Journal of the American Statistical Association, Vol. 71, pp. 378-385.

[29]Lemmens, A., Croux, C. and Dekimpe, M.G. (2005). 'On the predictive content of production surveys: A pan-European study', International Journal of Forecasting, Vol. 21, pp. 363-375. 
[30]Mauro P. (2003). 'Stock returns and output growth in emerging and advanced economies', Journal of Development Economics, Vol. 71, pp. 129-153.

[31]Moneta F. (2005). 'Does the yield spread predict recessions in the euro area?' International Finance, Vol. 8(2), pp. 263-301.

[32]Panopoulou E (2007) 'Predictive financial models of the euro area: A new evaluation test', International Journal of Forecasting (forthcoming).

[33]Panopoulou, E. Pittis, N. and Kalyvitis, S. (2006), 'Looking far in the past: Revisiting the growth-returns nexus with non-parametric tests'. Downloadable from: http://www.aueb.gr/Users/kalyvitis/

[34]Plosser, C. and Rouwenhorst G. (1994). 'International term structures and real economic growth', Journal of Monetary Economics, Vol. 33, pp. 33-55.

[35]Schwert, W. (1990). 'Stock returns and real activity: a century of evidence', Journal of Finance, Vol. 45, pp. 1237-57.

[36]Sensier, M., Artis, M., Osborn, D.R. and Birchenhall, C. (2004). 'Domestic and international influences on business cycle regimes in Europe', International Journal of Forecasting, Vol. 20, pp. 343-357.

[37]Stock, J., and Watson, M.(1989). 'New indexes of coincident and leading economic Indicators' in NBER Macroeconomic Annual, ed. O.J. Blanchard and S. Fischer, Cambridge, MA: MIT Press.

[38]Stock, J.H and Watson, M.W. (2003). 'Forecasting output and inflation: the role of asset prices', Journal of Economic Literature, Vol. 41, pp. 788-829. 
Table 1. Bivariate cross-country analysis for testing whether term spread in country $\mathbf{j}$ (jth column) Granger causes output growth in country i (ith row)

\begin{tabular}{|c|c|c|c|c|c|c|c|c|c|c|c|c|}
\hline Country & Austria & Belgium & Finland & France & Germany & Greece & Ireland & Italy & Luxembourg & Netherlands & Portugal & Spain \\
\hline Austria & 0.095 & 0.107 & 0.381 & 0.154 & 0.223 & 0.212 & 0.937 & 0.084 & 0.103 & 0.490 & 0.715 & 0.075 \\
\hline Belgium & 0.049 & 0.008 & 0.434 & 0.004 & 0.049 & 0.157 & 0.544 & 0.015 & 0.060 & 0.548 & 0.726 & 0.077 \\
\hline Finland & 0.305 & 0.604 & 0.456 & 0.130 & 0.062 & 0.004 & 0.164 & 0.413 & 0.024 & 0.008 & 0.029 & 0.445 \\
\hline France & 0.227 & 0.959 & 0.564 & 0.072 & 0.198 & 0.059 & 0.866 & 0.370 & 0.177 & 0.205 & 0.991 & 0.694 \\
\hline Germany & 0.001 & 0.044 & 0.171 & 0.024 & 0.003 & 0.186 & 0.149 & 0.088 & 0.294 & 0.105 & 0.064 & 0.138 \\
\hline Greece & 0.031 & 0.010 & 0.564 & 0.080 & 0.457 & 0.550 & 0.715 & 0.740 & 0.192 & 0.464 & 0.699 & 0.718 \\
\hline Ireland & 0.200 & 0.427 & 0.853 & 0.038 & 0.409 & 0.212 & 0.521 & 0.372 & 0.211 & 0.107 & 0.790 & 0.312 \\
\hline Italy & 0.063 & 0.110 & 0.770 & 0.053 & 0.077 & 0.193 & 0.609 & 0.250 & 0.032 & 0.055 & 0.351 & 0.102 \\
\hline Luxembourg & 0.908 & 0.897 & 0.431 & 0.895 & 0.283 & 0.402 & 0.161 & 0.522 & 0.721 & 0.793 & 0.529 & 0.294 \\
\hline Netherlands & 0.006 & 0.007 & 0.155 & 0.224 & 0.034 & 0.509 & 0.035 & 0.054 & 0.214 & 0.006 & 0.615 & 0.005 \\
\hline Portugal & 0.084 & 0.585 & 0.548 & 0.535 & 0.090 & 0.484 & 0.415 & 0.692 & 0.315 & 0.514 & 0.435 & 0.574 \\
\hline Spain & 0.021 & 0.264 & 0.573 & 0.010 & 0.011 & 0.011 & 0.372 & 0.117 & 0.351 & 0.048 & 0.610 & 0.399 \\
\hline
\end{tabular}

Notes: p-values. The bandwidth is 15 months. Bold indicates significance at the $10 \%$ level. 
Table 2. Bivariate cross-country analysis for testing whether stock market in country $i$ (ith row) Granger causes output growth in country j (jth column)

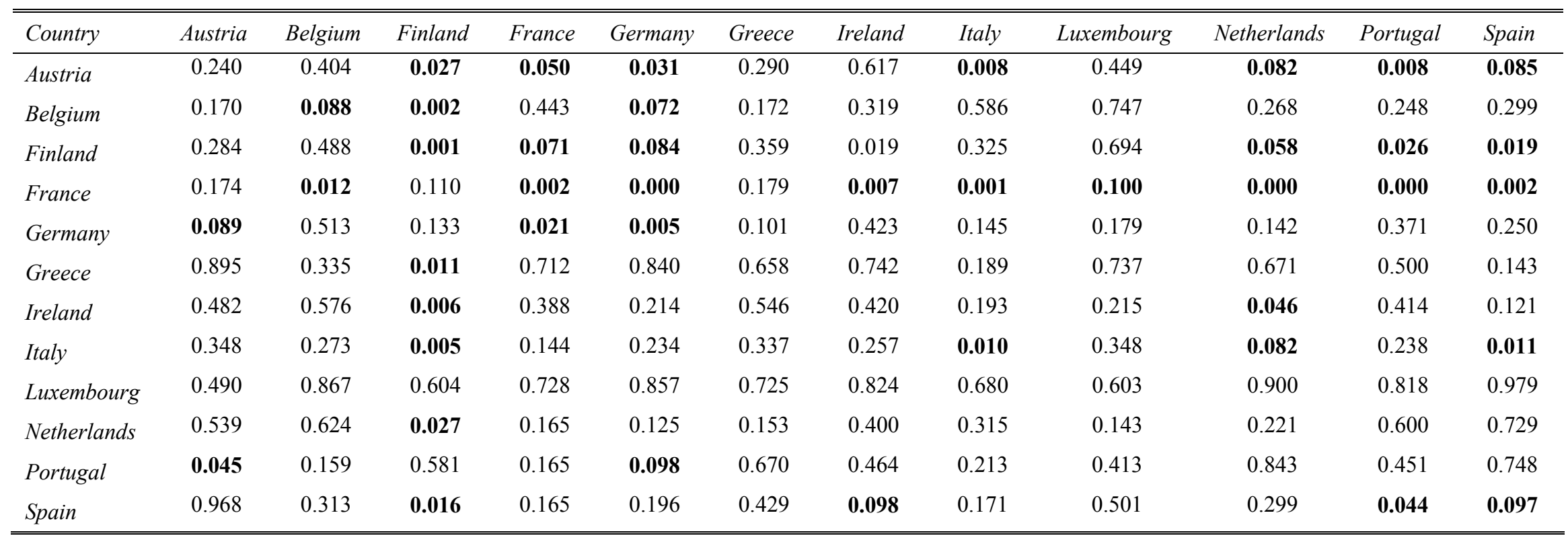

Notes: p-values. The bandwidth is 15 months. Bold indicates significance at the $10 \%$ level. 
Table 3. Bivariate cross-country analysis for testing whether money supply in country i (ith row) Granger causes output growth in country j (jth column)

\begin{tabular}{|c|c|c|c|c|c|c|c|c|c|c|c|c|}
\hline Country & Austria & Belgium & Finland & France & Germany & Greece & Ireland & Italy & Luxembourg & Netherlands & Portugal & Spain \\
\hline Austria & 0.032 & 0.099 & 0.184 & 0.021 & 0.896 & 0.355 & 0.029 & 0.157 & 0.068 & 0.269 & 0.487 & 0.342 \\
\hline Belgium & 0.003 & 0.189 & 0.177 & 0.000 & 0.270 & 0.359 & 0.249 & 0.245 & 0.672 & 0.226 & 0.801 & 0.856 \\
\hline Finland & 0.056 & 0.081 & 0.020 & 0.765 & 0.417 & 0.553 & 0.297 & 0.369 & 0.197 & 0.251 & 0.005 & 0.253 \\
\hline France & 0.084 & 0.199 & 0.328 & 0.732 & 0.378 & 0.253 & 0.197 & 0.237 & 0.395 & 0.158 & 0.420 & 0.027 \\
\hline Germany & 0.102 & 0.013 & 0.608 & 0.680 & 0.244 & 0.272 & 0.140 & 0.831 & 0.034 & 0.335 & 0.057 & 0.002 \\
\hline Greece & 0.451 & 0.519 & 0.309 & 0.391 & 0.002 & 0.782 & 0.252 & 0.880 & 0.220 & 0.233 & 0.413 & 0.260 \\
\hline Ireland & 0.971 & 0.781 & 0.921 & 0.393 & 0.594 & 0.349 & 0.041 & 0.869 & 0.830 & 0.596 & 0.221 & 0.949 \\
\hline Italy & 0.530 & 0.296 & 0.230 & 0.209 & 0.370 & 0.517 & 0.196 & 0.977 & 0.663 & 0.317 & 0.759 & 0.308 \\
\hline Luxembourg & 0.176 & 0.039 & 0.744 & 0.070 & 0.550 & 0.956 & 0.185 & 0.629 & 0.482 & 0.026 & 0.110 & 0.556 \\
\hline Netherlands & 0.111 & 0.018 & 0.066 & 0.016 & 0.023 & 0.339 & 0.526 & 0.321 & 0.070 & 0.210 & 0.224 & 0.110 \\
\hline Portugal & 0.217 & 0.921 & 0.355 & 0.081 & 0.550 & 0.606 & 0.486 & 0.821 & 0.867 & 0.084 & 0.977 & 0.822 \\
\hline Spain & 0.142 & 0.001 & 0.069 & 0.216 & 0.053 & 0.573 & 0.133 & 0.766 & 0.000 & 0.485 & 0.128 & 0.051 \\
\hline
\end{tabular}

Notes: p-values. The bandwidth is 15 months. Bold indicates significance at the 10\% level. 
Table 4. Multivariate cross-country analysis for testing whether financial variables cause output growth

\begin{tabular}{lccc}
\hline \hline Variable/lag & Term spread & Stock market & Money supply \\
\hline 3 & $p$-value & $p$-value & $p$-value \\
\hline 6 & 0.198 & 0.432 & $\mathbf{0 . 0 1 3}$ \\
9 & $\mathbf{0 . 0 9 6}$ & $\mathbf{0 . 0 9 7}$ & $\mathbf{0 . 0 8 5}$ \\
12 & 0.209 & 0.155 & $\mathbf{0 . 0 9 4}$ \\
15 & 0.128 & 0.298 & $\mathbf{0 . 0 8 1}$ \\
18 & $\mathbf{0 . 0 2 5}$ & 0.648 & $\mathbf{0 . 0 5 1}$ \\
\hline \hline
\end{tabular}

Note: Bold indicates significance at the $10 \%$ level.

Table 5. Clout/Receptivity

\begin{tabular}{lcccccc}
\hline \hline Country/variable & \multicolumn{2}{c}{ Term spread } & \multicolumn{2}{c}{ Stock } & market & \multicolumn{2}{c}{ Money supply } \\
\hline Clout & Recepti & Clout & Recepti & Clout & Recepti \\
vity & vity \\
Belgium & $\mathbf{0 . 0 0 0}$ & $\mathbf{0 . 0 0 2}$ & $\mathbf{0 . 0 1 9}$ & $\mathbf{0 . 0 0 0}$ & $\mathbf{0 . 0 0 5}$ & $\mathbf{0 . 0 0 4}$ \\
Finland & $\mathbf{0 . 0 0 3}$ & $\mathbf{0 . 0 0 0}$ & 0.221 & $\mathbf{0 . 0 0 0}$ & $\mathbf{0 . 0 0 0}$ & $\mathbf{0 . 0 0 1}$ \\
France & 0.203 & $\mathbf{0 . 0 0 0}$ & 0.250 & $\mathbf{0 . 0 0 0}$ & $\mathbf{0 . 0 4 8}$ & $\mathbf{0 . 0 0 0}$ \\
Germany & $\mathbf{0 . 0 0 0}$ & $\mathbf{0 . 0 2 3}$ & 0.148 & $\mathbf{0 . 0 0 0}$ & $\mathbf{0 . 0 0 0}$ & $\mathbf{0 . 0 0 0}$ \\
Greece & $\mathbf{0 . 0 0 1}$ & $\mathbf{0 . 0 0 0}$ & $\mathbf{0 . 0 6 2}$ & $\mathbf{0 . 0 0 0}$ & $\mathbf{0 . 0 7 2}$ & $\mathbf{0 . 0 0 1}$ \\
Ireland & 0.353 & $\mathbf{0 . 0 1 3}$ & 0.179 & $\mathbf{0 . 0 0 1}$ & 0.677 & $\mathbf{0 . 0 0 0}$ \\
Italy & 0.277 & 0.397 & 0.159 & $\mathbf{0 . 0 0 0}$ & 0.718 & 0.383 \\
Luxembourg & 0.145 & $\mathbf{0 . 0 0 0}$ & $\mathbf{0 . 0 1 4}$ & $\mathbf{0 . 0 0 1}$ & $\mathbf{0 . 0 0 2}$ & $\mathbf{0 . 0 1 3}$ \\
Netherlands & 0.347 & 0.377 & 0.487 & 0.320 & 0.144 & $\mathbf{0 . 0 0 0}$ \\
Portugal & $\mathbf{0 . 0 4 7}$ & $\mathbf{0 . 0 0 0}$ & 0.449 & $\mathbf{0 . 0 2 1}$ & $\mathbf{0 . 0 5 5}$ & $\mathbf{0 . 0 0 3}$ \\
Spain & 0.550 & 0.893 & 0.323 & 0.936 & 0.121 & 0.937 \\
\hline
\end{tabular}

Notes: p-values. The bandwidth is 15 months. Bold indicates significance at the $10 \%$ level. 